\title{
Creatividad en la plástica: historia de la construcción social del sujeto creativo
}

\section{Roxana Sosa}

\begin{abstract}
SÍNTESIS
El presente trabajo consiste en un breve análisis sobre el pensamiento creativo contemplado desde la perspectiva artística. Para ello abordamos el papel del sujeto creador como pieza fundamental para que el arte consiga hacerse efectivo, constatando cómo ese sujeto se ha ido configurando a través de la historia gracias a la negación de otros sujetos, y entre ellos, las mujeres artistas. En este sentido la creación artística se ha visto tradicionalmente en manos de los hombres y éstos han trasladado a sus obras lo que era dominante en la sociedad, resultando, en consecuencia, que la relación mujer/arte se ha visto condicionada por un carácter sexista.
\end{abstract}

\begin{abstract}
This paper is a brief analysis of creative thinking considered from the artistic perspective. For this approach the role of the creative subject as fundamental to art that gets made effective, noting how this individual has been shaped through history thanks to the denial of other subjects, and among women artists. In this sense the artistic creation has been traditionally held by men, and they have moved to their works that was dominant in society, being thus the ratio of women to art has been conditioned by a sexist.
\end{abstract}

Palabras clave: Creación, arte, canon, feminismo, identidad.

Key words: Creation, art, canon, feminism, identity.

\section{Introducción}

El pensamiento creativo consiste en la capacidad del ser humano para desarrollar nuevas ideas o conceptos y por ser éstos originales. Dentro del análisis del pensamiento creativo ocupa un lugar preponderante la creación artística, concebida como forma de comunicación y de expresión máxima de los seres humanos.

En este artículo ofrecemos una reflexión sobre el pensamiento creativo contemplado desde la dimensión artística, por considerarlo como uno de los medios a través de los cuales una persona desarrolla una expresión original. 
El arte considerado en cuanto a despliegue de objetos artísticos necesita de las características de un sujeto creador para hacerse efectivo. En este sentido, se ha venido constatando, a través de la construcción social de la historia del arte, cómo este sujeto creador por excelencia tenía, entre otras, las siguientes atribuciones: masculino, blanco, genio, judeo-cristiano y occidental. De tal modo que la configuración de ese sujeto, como señala Marián Cao, "se hizo posible gracias a la negación de otros sujetos: de la misma manera que el norte económico subsiste gracias a la miseria del sur, el sujeto para sí se hizo desde la negación de la autonomía de los otros. Los otros, todos los demás y, entre ellos, las mujeres" (Cao, 2000, 15).

Como analizamos en este artículo, la construcción de ese sujeto creativo que se ha venido configurando a través de la historia es una construcción basada en un paradigma que excluye de partida a la mujer.

\section{Las mujeres creadoras a través de la historia}

La presencia real de las mujeres en el panorama artístico tiene su origen en la denominada época de las vanguardias históricas, momento que corresponde al período de entreguerras. La presencia real de las mujeres como artistas, y no sólo como compañeras, comenzó a ser destacable en el marco del expresionismo alemán, adquiriendo gran relevancia durante la Rusia pre y post-revolucionaria, para alcanzar una presencia nada desdeñable con la llegada del movimiento surrealista. El inicio de los primeros movimientos de emancipación de la mujer y las luchas sufragistas, que discurren paralelos al desarrollo del siglo $\mathrm{XX}$, sentarán las bases hacia lo que será, en los años setenta y ochenta, la presencia activa de la mujer en el arte.

Ha habido mujeres artistas pero sus creaciones han sido atribuidas a los hombres - padres, amigos o maestros- o bien han sido minimizadas. Las biografías existentes sobre las obras de mujeres artistas, afirma Marián Cao, "No se refieren a éstas como entes autónomos sino como hijas, esposas o madres, o en otros casos, las minimizan al dedicarse a géneros bajos, como el retrato, flores, bodegones, etcétera" $(2000 B, 23)$. 
Al desarrollar este artículo sobre la exclusión de la mujer en la creación artística, hemos de destacar que muchas artistas trabajaron en el aislamiento y fueron relegadas y silenciadas, sistemáticamente, de los movimientos artísticos. Sólo en parte fueron recuperadas del olvido debido a la labor investigadora de las historiadoras del arte feministas. Hoy es posible conocer a muchas creadoras gracias a la tarea de recopilación histórica realizada fundamentalmente por críticas de arte como Linda Nochlin o Lucy Lipard, entre otras autoras, quienes, a partir de los años sesenta del siglo XX, cuestionan en libros y artículos los fundamentos de la historia del arte tradicional, así como el aislamiento en el que trabajaron gran parte de las creadoras motivó su exclusión de los principales movimientos artísticos. Estas autoras revelan, entre otros aspectos, la estructura básica sobre la que se habían confeccionado los textos artísticos, asimismo analizan la manera en que las mujeres y sus producciones han sido presentadas en relación negativa con la creatividad y la alta cultura. A partir de ese período (años sesenta), comienza la construcción de una historia paralela por parte de las críticas de arte feministas, que comienzan a publicar libros y artículos donde cuestionan los cimientos mismos de la historia del arte que, sistemáticamente, había descolgado las producciones de las mujeres relegándolas al papel de objetos artísticos, en lugar de sujetos de éste.

La historia del arte oficial que nos ha sido transmitida ha ido construyendo durante siglos sus propios códigos internos, y se ha elaborado privilegiando, no sólo a determinados grupos sociales, sino también preponderando aspectos relacionados con el arte tales como: estilo artístico, el formato monumental, la autenticidad, la técnica, el valor de la obra, así como al descubrimiento del artista. En este proceso de reflexión y clasificación, la historia ha definido al artista con estas características: varón, héroe, demiurgo y genio creador. Esta concepción ha dejado un margen muy limitado para cuadros de pequeñas dimensiones de mujeres con una técnica propia y consistente, como es el caso de obras de mujeres artistas como Gwen John, o Florine Stettheimer, por citar dos conocidos ejemplos.

La preponderancia de lo monumental en la historia de la creación también ha contribuido a la exclusión de muchas mujeres artistas que hubieron de conjugar responsabilidades domésticas con la creación. Esta concepción de artista entraña, como 
sostiene Whitney Chadwick, "una visión del arte como expresión individual que refleja una sociedad determinada con sus características sociales, políticas y económicas" $(1992,10)$.

En este proceso de clasificación, lo distintivo de la historia del arte es una férrea división entre el artista como persona individual, por un lado, y sus condiciones socio-históricas, por otro. Se da una escisión entre la construcción de su historia individual y el contexto donde se desarrolla, así como de las condiciones sociales de la producción creadora.

\section{Cuestionamiento del canon en la creación artística}

La historia del arte creó un canon que vinculaba riqueza, poder y privilegios de diversos grupos sociales con determinados sectores que encargaron las obras de arte o las adquirieron, así como con todos aquellos hombres que escribieron sobre ellas y las identificaron como arte. Este canon determinó y modeló los campos de la creatividad, y fue establecido por los varones según un modelo de supuesta universalidad, y que resultaba ser el producto de una visión parcial y excluyente. En nuestros días, no sólo el canon respalda mayoritariamente a los varones creadores, sino que también se ve favorecido por medio de las prácticas de apoyo que sustentan el entramado artístico, que continúan estando dominadas por varones. Estas prácticas se sostienen básicamente a través de los distintos canales de difusión artística: antológicas, retrospectivas, bienales, comisariados de exposiciones, así como un elenco de personas que contribuyen a crear el conocimiento artístico. Estas redes de apoyo se van creando desde los años de estudio de la universidad, consolidándose con arraigo al finalizar la misma.

En este sentido el canon no es monolítico, a pesar de su vigencia, y el consenso que se mantuvo a lo largo de los años comenzó a cuestionarse.

El contradiscurso femenino sobre la creatividad, la importancia de la identidad, así como de la redefinición conceptual del arte y de la cultura, empezó a plantearse en la década de los años sesenta del siglo XX, a través de la toma de conciencia de su condición por parte de las mujeres artistas procedentes, 
especialmente, del mundo anglosajón, dando lugar a un tratamiento feminista en sus planteamientos creativos.

Los años sesenta suponen el inicio de una década emblemática en todo el mundo desarrollado. A este respecto cabe señalar la importancia que tuvo el comienzo, en esa época, del movimiento feminista contemporáneo, coincidiendo en el tiempo con otros movimientos de liberación, minorías y descolonización. De este modo la lucha de la mujer confluye con la lucha de los pueblos oprimidos por su emancipación.

En este sentido, las obras de arte de esa época se conciben como crítica a la ideología sociopolítica. Tratan de transformar las relaciones de poder insertas en la sociedad, cuestionando los valores estéticos. Pero en esa construcción de la conciencia feminista, y por tanto del activismo contra la visión (patriarcal) dominante, la acción emprendida por el feminismo no se convirtió en una postura unidireccional, sino que abrió un debate en torno a qué reivindicar, cómo hacerlo, qué estrategias utilizar, etc. Aparecieron propuestas heterogéneas que se pueden agrupar en dos enfoques básicos que tuvieron una distancia temporal: feminismo de la igualdad y feminismo de la diferencia. El debate entre uno y otro se centró en torno a la existencia o no de una esencia femenina distinta a la del varón.

El feminismo de la diferencia, también calificado como feminismo esencialista, señalaba el carácter femenino como específicamente diferente al masculino. La teoría de la diferencia sostiene que es el momento de privilegiar unas categorías distintas a las privilegiadas históricamente por el varón, así estaremos en condiciones de equilibrar tantos siglos de desigualdad. El feminismo de la diferencia apareció con más fuerza en los años sesenta y setenta, especialmente en el mundo anglosajón. Artistas como Judy Chicago y Miriam Schapiro son representativas de esta teoría, y realizaron un arte que abandonó la producción de esculturas abstractas y geométricas para realizar obras específicamente femeninas, tomando como punto de reflexión su propia identidad y sus propios cuerpos.

Judy Chicago (Chicago, 1929) imprime en sus obras un carácter marcadamente feminista, donde aparecen formas cuya iconografía recuerda a las flores abiertas de Georgia O’Keeffe, como la titulada Quitando la piel (1974), concebida como un intento de transformar el sexo femenino -entendido hasta entonces como 
algo pasivo- en algo activo. Su obra más conocida y polémica fue la titulada La cena (1974). La obra rinde homenaje a las contribuciones históricas y culturales de las mujeres. Cuenta con treinta y nueve asientos como dedicatoria a treinta y nueve mujeres por su contribución a las artes, la literatura y la política. En cada asiento aparece un plato de cerámica que contiene un motivo central diseñado por la artista y simboliza a la mujer a la que se le homenajeaba, así como un tapete cosido según técnicas del bordado, adaptadas al período histórico de cada personaje.

Miriam Schapiro (Toronto, 1923) utilizó para la confección de sus obras la artesanía del tejido. Para ello creó patrones decorativos no occidentales (como los islámicos y japoneses). Realizó también algunas obras combinando técnicas como el collage, el assemblage, découpage, junto con técnicas tradicionales femeninas como el ganchillo, la costura, etc. La intención de la artista era acabar con las fronteras marcadas por la cultura masculina europea entre el high art y la artesanía.

El feminismo de la igualdad, o también denominado antiesencialista o posmoderno, fue defendido, por el contrario, en los años ochenta. Sostiene que privilegiar un sexo en detrimento de otro no es más que caer en otra jerarquización y en un error similar al propuesto por el modelo dominante (patriarcal). Este feminismo intenta reconstruir las estructuras patriarcales, pero reivindicando la igualdad desde la diferencia, sin caer en las eternas descalificaciones. La unión entre feminismo y posmodernismo tuvo como aportaciones más evidentes los trabajos de dos artistas representativas de este periodo: Barbara Kruger y Jenny Holzer. Ambas reflexionan sobre la identidad al igual que lo hace Cindy Sherman, pero utilizando distintos procedimientos.

Barbara Kruger (Nueva Jersey, 1945). A comienzos de la década de los años ochenta obtuvo un reconocimiento dentro del mundo artístico con obras donde combinaba fotografías en blanco y negro con textos. Utilizaba para ello estrategias propias de los anuncios publicitarios; no en vano había trabajado como diseñadora gráfica para revistas como Vogue y Mademoiselle. El lenguaje utilizado por Kruger como vehículo para objetar el discurso dominante, y la utilización conjunta de una imagen manipulada y ampliada de la mujer reducida a un estereotipo social, actúan como cuestionadores, no sólo del lenguaje dominante de los medios de comunicación de masas, sino que también 
denuncian el rol pasivo que tradicionalmente se asigna a la mujer en la cultura patriarcal.

Jenny Holzer (Ohio, 1950). Es una artista que cuestiona con sus propuestas otra forma de presentar el arte fuera de sus contenedores habituales, a saber, el museo o la galería. En un primer momento la artista pegó sus obras mecanografiadas en las calles del Soho y Manhattan. Posteriormente éstas fueron impresas en camisetas, cabinas telefónicas y fachadas de edificios. Como Barbara Kruger, debate el lenguaje dominante de los medios de comunicación de masas y la publicidad. Para ello no duda en utilizar las estrategias propias de estos medios sirviéndose de sus posibilidades efectistas.

Cindy Sherman (Nueva Jersey, 1954) es una de las artistas que mejor representa el arte de la igualdad de los años ochenta. $\mathrm{Al}$ mismo tiempo es una de las máximas exponentes del arte del cuerpo, reivindicando un sujeto femenino múltiple y fragmentario. Desde sus inicios ha utilizado el soporte fotográfico. Sherman se fotografía a sí misma asumiendo una diversidad de personalidades de mujer: la mujer coqueta, la sumisa, la intelectual, el ama de casa, la secretaria, etc. En sus fotografías coexiste el teatro, la performance y el travestismo, que controla con sus gestos para congelarlos en una instantánea fotográfica. Más adelante, la artista recurre a aspectos que la sociedad considera como aberrantes, o incluso tabú. Así, trabajos como Desastres (1985), aparecen figuras de malformaciones, asociadas a la anorexia (restos de comida), o sangre menstrual. En este sentido la artista revaloriza aspectos de la experiencia corporal que son censurados por la cultura patriarcal. En su obra intermedia de los años 1987 a 1990, la artista continúa su reflexión crítica sobre la identidad femenina, y, al mismo tiempo, Sherman ridiculiza la historia del arte con una serie de retratos y modelos del renacimiento y del barroco, donde aparecen alusiones explícitas a los grandes pintores como Raphael, Caravaggio, Ingres, etc. En las obras de los años 1992 a 1996, la artista presenta trozos y fragmentos del cuerpo: brazos, piernas, torsos mutilados o desmembrados que hablan de una sociedad marcada por la violencia. De esta época será su serie titulada Sex Pictures (1992), donde representa la transformación en objeto del ser humano.

Con sus reflexiones, las artistas de ese período contribuyeron a destacar un posicionamiento de la mujer como sujeto creador 
activo, en contraste con la tradicional representación por parte de los artistas varones. Esta reivindicación estuvo en parte inspirada en la obra de Simone de Beauvoir El segundo sexo, publicada en Francia en 1949, donde la autora realiza un análisis de la condición femenina en las sociedades occidentales.

La creación artística se implicará en las luchas feministas con una considerable carga política. De este modo el arte feminista, como apunta Juan Luis Martín Prada en Arte Feminista y Esencialismo:

Reemplazó el monólogo moderno y egoísta por un diálogo entre las artistas, no sólo del presente, sino también entre éstas y las artistas del pasado. Frente al aislamiento creativo del artista, el arte feminista va a ser deliberadamente incisivo en el contexto social y público, caracterizado por un elemento de otredad, es decir, de una necesidad de conexión más allá del producto y del proceso artístico $(2000,148)$.

Parece interesante hablar de unos caminos por los que va a gravitar la creación artística femenina, en contraposición con la creación tradicional masculina. Estos serían: un deseo de expresar lo personal, la importancia del tema en detrimento de la forma, la relación entre arte y experiencia cotidiana, y la búsqueda de lo femenino alejado de planteamientos fetichistas.

En 1971, la crítica feminista Linda Nochlin, analizando las obras de las artistas y sus contribuciones de los años sesenta, destaca como representativa de la creación femenina el predominio de las imágenes centrales y la pintura de modelos, la disposición en capas, la fragmentación y el collage, así como la importancia del tema en detrimento de la forma, y el contenido autobiográfico en la performance y en el video, así como en los libros de artistas, la apropiación de formas de arte tradicional como el bordado, la costura y la pintura de porcelana.

La creación feminista es, ante todo, una postura ideológica. Su propio término, "arte feminista", no implica un tratamiento formal o temático, y sí implica un aspecto distinto a la concepción masculina de arte; el interés del artista no es tanto la obra de arte en sí, sino que ésta es el resultado de una vivencia personal. Frente al aislamiento creativo del artista, el arte femenino va a ser deliberadamente incisivo en el contexto social y público, caracterizado por una necesidad de conexión más allá del producto y del proceso artísticos. 
Las artistas de los años sesenta y setenta tuvieron un papel destacable en la temática de la autorepresentación del cuerpo, $\mathrm{y}$, de hecho, se puede decir que fueron iniciadoras respecto a la sexualidad y al cuerpo femenino. Serían las primeras en criticar, ironizar y subvertir las imágenes de la mujer difundidas por la tradición del desnudo femenino. Con sus reflexiones contribuyeron a destacar un posicionamiento de la mujer como sujeto activo en la autorepresentación de su cuerpo, y no como se había venido exponiendo hasta ahora, a saber, como mero objeto sexual por parte de los artistas varones. Las artistas de este período que toman la iconografía del cuerpo como reflexión y práctica artística, tratan de hacer visible un cuerpo que ha sido omitido por el arte, manifestando sus experiencias, sus sentimientos, pero desde una visión propia, y revelando el interior del cuerpo, a diferencia de la tradición del desnudo femenino que ponía el énfasis en el exterior del cuerpo. Muchas artistas, en este contexto, orientan su trabajo a cuestionar las imágenes de la mujer difundidas en la tradición del desnudo femenino.

$\mathrm{El}$ arte realizado en este contexto se distingue por ser un arte autobiográfico definido por el uso de una diversidad de medios, soportes, modelos e intenciones, que conjugan un desarrollo plástico individual con actuaciones colectivas, involucrándose en reivindicaciones defendidas por los movimientos sociales del momento. Por encima de todo, el arte femenino logra desafiar la norma dominante acerca de la sexualidad y el género; respaldado por el movimiento feminista involucra a artistas, críticas y otros colectivos implicados en el mundo del arte (galerías, revistas, espacios alternativos, etc.).

Los códigos visuales utilizados por las artistas de los sesenta y setenta proporcionaron nuevas imágenes e interpretaciones sobre las mujeres y los hombres, y reflejaron, como apunta Lourdes Méndez, "Por primera vez, la voluntad expresiva de unas artistas que no se plegaban a la imaginería canónica" $(2004,101)$.

\section{Conclusión}

Como hemos venido analizando a través de este artículo, la creación aplicada al mundo del arte se ha basado en una concepción que 
refleja a un sujeto creador con unas características determinadas: varón, blanco, occidental y judeo-cristiano, y concede un ámbito limitado al estatuto de mujer creadora. La historia del arte, en tanto mecanismo sancionador de valores estéticos, constituye un gran filtro, e inmortaliza en libros, manuales y catálogos, sólo aquello que es afín a su propia ideología. En este sentido la creación artística se ha visto tradicionalmente en manos de los hombres y éstos han trasladado a sus obras lo que era dominante en la sociedad, resultando, en consecuencia, que la relación mujer/ arte se ha visto condicionada por un carácter sexista. Al propio tiempo la historia del arte, en tanto disciplina científica, ha exhibido en su mirada un marcado carácter androcéntrico, además de etnocentrista y sesgado. Es el varón el que hoy todavía determina y modela los campos de la creatividad, el que todavía habla de las artes menores femeninas, del ornamento. El del arte es un campo que en buena medida sigue estando en manos masculinas; ellos son los gestores, los artistas, los críticos y los galeristas. La representación de las mujeres artistas en los museos y en las exposiciones de carácter colectivo continúa siendo escasa.

Una de las conclusiones principales que se desprende del artículo es que las condiciones socioeconómicas y políticas afectan a las condiciones sociales de producción de las mujeres, y están presentes también en las artes plásticas, condicionando la visibilidad de las mujeres artistas. A pesar de los avances existentes en el terreno de la igualdad, gracias en buena medida a la herencia de las luchas tanto de artistas como de críticas de arte vinculadas al movimiento feminista, la estructura socioeconómica y política sigue estando en manos de un poder masculino que favorece $y$ privilegia la presencia de varones artistas en las distintas parcelas del campo artístico. Recordemos la famosa interrogante citada por Linda Nochlin en el año 1971 (¿Por qué no ha habido grandes mujeres artistas?) con el que planteaba la propuesta de que si en la historia del arte no se había conocido a grandes mujeres artistas era consecuencia de las peculiares circunstancias históricas que habían envuelto a las mujeres, limitando su despliegue social, económico y cultural.

En definitiva, considero que una de las principales propuestas que pueden modificar el panorama de la creación artística en la sociedad y del rol de la mujer en el mismo, proviene del papel de la educación como mecanismo favorecedor de la equidad. 


\section{Bibliografía}

Apple, Michael. Educación y poder. Barcelona: Paidós, 1987.

Bartra, Eli. Mujer, Ideología y Arte. Barcelona: La Sal. 1987.

Cao, Marián. Creación Artística y Mujeres. Recuperar la Memoria. Madrid: Narcea, 2000.

Chadwick, Whitney. Mujer, Arte y Sociedad. Barcelona: Destino, 1992.

Freixas, Laura. Literatura y Mujeres. Barcelona: Destino, 2000.

Martín Prada, Juan. Luis. “Arte Feminista y Esencialismo”, en Cao, 2000.

Mayayo, Patricia. Historias de mujeres, Historias del arte. Madrid: Cátedra, 2003.

Méndez, Lourdes. Cuerpos sexuados y ficciones identitarias. Ideologías sexuales, deconstrucciones feministas y artes visuales. Sevilla: Instituto Andaluz de la Mujer, 2004.

Millet, Katte. Política sexual. Madrid: Cátedra, 1995.

Nead, Linda. El desnudo femenino: arte, obscenidad y sexualidad. Madrid: Tecnos, 1998.

Serrano De Haro, Amparo. Mujeres en el Arte, Espejo y Realidad. Barcelona: Plaza y Janés, 2000.

Solans, Piedad. Accionismo vienés. Madrid: Nerea, 2000. 